\title{
Uma solução baseada no realismo experimental para dois argumentos pessimistas
}

An experimental realism based solution for two pessimistic inductions

\begin{abstract}
Resumo: No presente trabalho procurarei expor dois desafios antirrealistas ancorados na história da ciência, que Stanford (2006) apelidou respectivamente de 'antiga' e 'nova indução pessimista'. Argumentarei que existe uma solução realista já disponível a ambos os desafios pessimistas: o realismo experimental, inicialmente proposto por Hacking (1983) e Cartwritght (1983), segundo o qual é possível comprometer-se com entidades teóricas com as quais desenvolvemos interações causais e com as quais produzimos fenômenos controlados, sem que tal compromisso se estenda às teorias mesmas. Tomarei como parâmetro não propriamente os argumentos de Hacking e Cartwright que sofrem inúmeras críticas, mas uma formulação sofisticada do realismo experimental proposta por Egg (2012).

Palavras-chave: Indução Pessimista, Problema das alternativas não concebidas, Realismo experimental, Realismo causal.
\end{abstract}

\begin{abstract}
In this paper, I will try to give an account of two historically informed antirealist challenges named by Stanford (2006) as 'old' and 'new pessimistic induction', respectively. I argue that there is already an answer to both pessimistic challenges: the experimental realism originally proposed by Hacking (1983) and Cartwright (1983). According to that realism, it is possible to be committed to theoretical entities with which we develop causal interactions and produce controlled phenomena, even without extending that commitment to theories themselves. Instead of taking properly Hacking's and Cartwright's widely criticized arguments, I will assume a sophisticated experimental realism formulation put forward by Egg (2012)
\end{abstract}

Keywords: Pessimistic induction, Problem of unconceived alternatives, Experimental Realism, Causal realism. 


\section{Introdução}

O filósofo Kyle Stanford (2006) sugeriu que o realismo científico (tese segundo a qual a ciência madura exibe conhecimento aproximado da realidade observável e inobservável) sofreria a ameaça de duas induções pessimistas. A primeira ameaça, também chamada de metaindução pessimista, é derivada do artigo de Laudan (1981), segundo o qual há uma série de teorias obsoletas na história da ciência que a seu tempo gozaram do sucesso preditivo e explicativo e que à luz da ciência atual podem ser consideradas falsas. A segunda ameaça seria um desafio original proposto por Stanford e foi por ele chamado de o problema das alternativas não concebidas. Tal nova indução ressaltaria a emergência de teorias concorrentes compatíveis com os mesmos dados empíricos ao longo da história da ciência, mesclando o problema da subdeterminação da teoria pela evidência empírica e indução pessimista original.

Ao longo deste trabalho, procuraremos evidenciar as ameaças que ambos os desafios apresentam ao realismo científico, ao mesmo tempo em que tentaremos superá-los com uma versão mais robusta de realismo experimental, baseada sobretudo em Egg (2012, 2014), mas influenciada também por Chakravartty $(2007,2008)$ e Suárez (2008). Entendemos que o realismo experimental proposto por Hacking (1983) e Cartwright (1983) já constituía uma resposta plausível à descontinuidade da ciência ressaltada pela metaindução pessimista. Os esforços de Egg (2012) em corrigir e aperfeiçoar as intuições do realismo experimental resultam em uma resposta igualmente consistente para o problema das alternativas não concebidas.

Para cumprir nossos objetivos, dividiremos o nosso trabalho em três blocos, o primeiro dos quais dedicado aos dois argumentos pessimistas e seu lugar no debate em torno do realismo científico, o segundo ao realismo causal de Egg (2012) e o último mostrando como tal proposta realista se compatibiliza com a história de descontinuidade de teorias científicas.

\section{Dois argumentos pessimistas}

a) O primeiro argumento pessimista 
A metaindução pessimista é um argumento historicista segundo o qual a ciência seria um cemitério de teorias e entidades, fato que lança pessimismo no projeto do realismo científico, de aproximação de uma descrição verdadeira da realidade. Uma das mais importantes contribuições para tal pessimismo foi o artigo intitulado $A$ confutation of covergent realism de Larry Laudan (1981), que surgiu como uma contenção ao argumento sem-milagre de Putnam (1975) em favor do realismo científico. De acordo com este último autor (em sua fase realista), o realismo científico "é a única filosofia que não faz do sucesso da ciência um milagre” (PUTNAM, 1975, p.73). O referido artigo de Laudan cita pelo menos 11 teorias que gozaram de sucesso em seu tempo e, de acordo com as teorias atualmente aceitas, são consideradas falsas. Outro problema também evidenciado pela lista de Laudan é que as entidades como éter, flogisto e calórico, supostas pelas teorias obsoletas, foram descartadas como ficções desnecessárias segundo a nova ontologia pensada com base na ciência atual.

Apesar do nome já incorporado no debate entre realismo e antirrealismo científico, entendemos que o desafio pessimista é melhor formulado como uma dedução ${ }^{2}$. Concordando com esse entendimento, Lyons (2002) renomeou o desafio historicista como um meta-modus tollens pessimista. Em sua perspectiva, a lista de Laudan serve como uma série de exemplos capazes de derrotar o argumento do milagre. Lyons procura mostrar que o realismo, ainda aquele modificado para acomodar boa parte da lista de Laudan, continua ameaçado por sua "nova" repaginação dedutiva da metaindução. O meta-modus tollens pessimista nada mais é do que uma formulação dedutiva da metaindução pessimista que contesta a relação entre sucesso e verdade. Segundo Lyons, o argumento dedutivo é bastante simples:

\footnotetext{
${ }^{2}$ Ver, por exemplo, uma proposta de formulação dedutiva da indução pessimista em OLIVEIRA, Tiago Luís Teixeira. Algumas razões para levar a sério a metaindução pessimista. Principia: an international journal of epistemology, [S.1.], v. 18, n. 2, p. 269-290, aug. 2014. ISSN 1808-1711.

Available at: <https://periodicos.ufsc.br/index.php/principia/article/view/1808-1711.2014v18n2p269 >. Date accessed: 30 june 2017. doi:http://dx.doi.org/10.5007/1808-1711.2014v18n2p26g.
} 
598 | Veritas | Porto Alegre, v. 62, n. 3, set.-dez. 2017, p. 595-623

Premissa 1: Se a hipótese realista está correta (A), então cada teoria de sucesso será verdadeira (B).

Premissa 2: Temos uma lista de teorias de sucesso que não são verdadeiras (não B).

Conclusão: Logo, a hipótese realista é falsa (não A). (LYONS, 2002, p. 65)

$\mathrm{Na}$ tentativa de estabelecer um realismo mais sofisticado e imune à lista de Laudan, autores como Lipton (1993 e 1994), Psillos (1996 e 1999) e Sankey (2001) procuraram especificar quais tipos de sucesso seriam indícios da verdade aproximada de uma teoria. A solução realista para o meta-modus tollens pessimista acima seria, portanto, afirmar a verdade aproximada somente das teorias capazes de fazer previsões de fenômenos antes desconhecidos e/ou capazes de explicar fenômenos que, apesar de conhecidos, não foram utilizados na sua formulação:

Novo sucesso pode ser dividido entre dois tipos: novidade temporal, no qual os fenômenos previstos são desconhecidos dos cientistas no tempo em que a previsão é derivada e novidade de uso, uma forma menos exigente, na qual os fenômenos podem ser conhecidos, mas não foram usados na formulação da teoria. (LYONS, 2002, p.69)

Ocorre que mesmo nessa formulação sofisticada, a hipótese realista enfrentaria os novos sucessos das teorias do calórico, do éter e do flogisto (já presentes na lista de Laudan), bem como de várias outras teorias consideradas falsas à luz de teorias atuais. Lyons cita um grande número de teorias em desuso que forneceram novas predições à sua época: a teoria do vórtice de Rankine, a teoria da molécula de benzeno de Kekulé, a teoria atômica de Dalton e a de Bohr, etc. Essas e outras formulações teóricas apresentaram à sua época novas previsões e os constituintes teóricos responsáveis pelo sucesso vieram a se mostrar mais tarde inúteis nas elaborações das teorias seguintes. Assim, tais novos sucessos serviriam como instâncias para o modus tollens de Lyons e mesmo modificando a primeira premissa para atermos somente ao sucesso surpreendente, o argumento funcionaria. Isso fica evidenciado também num texto de Peter Vickers, cujo nome é bastante sugestivo: $A$ confrontation of convergent realism (2013). No artigo, Vickers retoma a lista de Lyons (2002) e apresenta nada menos do que 20 teorias capazes de contestar a relação entre novas predições e verdade aproximada. Não 
temos a intenção de reproduzir aqui toda a lista de Lyons ou a de Vickers, mas a lição dada é a mesma: qualquer que seja a versão de realismo a ser construída, sua defesa precisa levar em conta os contraexemplos que a história da ciência oferece de modo a acomodar tais casos e a refinar os critérios do que é que deve ser retido e o que é que pode vir a ser substituído em uma futura mudança teórica. De acordo com Vickers, os 20 contraexemplos sugeridos podem ser apenas a ponta do iceberg dessa necessidade de refinamento e, apesar disso, ele parece otimista com a possibilidade de o realista oferecer ao menos um meio de descobrir quais são as peças soltas da engrenagem teórica:

$\mathrm{O}$ realismo divide et impera ${ }^{3}$ precisa ser desafiado por e desenvolvido à luz de todo o registro histórico. E esse registro é muito mais rico do que as discussões de longa duração de Fresnel, do calórico e do flogisto deixam aparecer. Os 20 exemplos apresentados (...) podem muito bem ser a ponta do iceberg. E cada exemplo tem o potencial de trazer algo novo para o debate. [...] Em tudo isso, encontramo-nos - mesmo 30+ anos depois de Laudan (1981) - inseguros da extensão do sucesso que a estratégia divide et impera pode ter. Mesmo se os 'postulados ativos' ('working posits') da ciência contemporânea não podem ser prospectivamente identificados, permanece possível que devamos desenvolver uma receita para identificar alguns postulados ociosos (idle posits). Isso seria um feito significante, mesmo se não for bem o que o realista originalmente tinha em mente. (VICKERS, 2013, p. 209)

A metaindução pessimista, pelo menos na sua formulação dedutiva, apresenta-se como desafio a qualquer realismo científico defensável. Sem um cuidado em acomodar a história da ciência como uma história de descontinuidade, seria muito difícil defender que a ciência madura exibe conhecimento da realidade inobservável. No mínimo, tal realismo teria de ser capaz de explicar a descontinuidade, oferecendo um critério para decidir sobre o que é mais e o que é menos provável de ser retido numa mudança teórica futura.

b) A nova indução pessimista

\footnotetext{
${ }^{3}$ Divide et impera foi o nome que Psillos $(1996,1999)$ deu a uma tentativa de reconhecimento de que há elementos de uma teoria que são responsáveis por seu sucesso, sem que a teoria tenha que ser considerada verdadeira ou falsa como um todo. Seria, portanto, uma forma de realismo seletivo, com graus de comprometimento epistêmicos diferentes para partes distintas da mesma teoria.
} 
O novo argumento pessimista que Stanford procura avançar foi exposto no livro Exceeding our grasp (2006) e é composto de dois passos: utilização do registro histórico para admitir a possibilidade de as teorias atuais estarem sujeitas ao mesmo destino.

Para o entendimento do primeiro passo (i), é preciso mencionar que há um outro tipo de argumento contrário ao realismo científico conhecido pelo nome de subdeterminação da teoria pela evidência empírica. Tal desafio antirrealista recai sobre os critérios de escolha dentre teorias rivais, uma vez que duas ou mais teorias podem ser suportadas pela mesma evidência empírica ${ }^{4}$ e, entretanto, mostrarem-se contraditórias entre si, propondo diferentes ontologias, descrevendo a mesma realidade de modo completamente distinto uma da outra. Tratase de uma possibilidade lógica segundo a qual se uma das teorias rivais é (aproximadamente) verdadeira, ainda que não saibamos qual delas, as suas alternativas empiricamente equivalentes seriam falsas, justamente por causa das diferentes ontologias em questão. O conceito que utilizo aqui para equivalência empírica é tal e qual o oferecido por Chakravartty:

Dada uma teoria, $\mathrm{T}_{1}$, é sempre possível gerar uma teoria empiricamente equivalente, mas diferente, $\mathrm{T}_{2}$. $\mathrm{T}_{2}$ é uma teoria que faz precisamente as

\footnotetext{
${ }^{4}$ A ideia suporte empírico subjacente ao argumento da subdeterminação da teoria pela evidência empírica depende claramente da escolha de uma teoria da confirmação, que poderia ser um modelo hipotético-dedutivo ou indutivo/probabilístico. O problema clássico da subdeterminação (que Stanford classificou como "em princípio") é bastante evidente no modelo dedutivo já que trata de uma possibilidade lógica de construir hipóteses alternativas capazes de fazer as mesmas previsões e dar explicações aos mesmos fenômenos, diferenciando-se na introdução ou supressão de entidades e/ou processos inobserváveis, deixando intocadas as reivindicações referentes aos fenômenos. Já uma teoria do suporte probabilístico parece precisar de mais recursos para possibilitar a existência de um problema da subdeterminação. Neste último caso, seria preciso que os mesmos fenômenos conferissem o mesmo grau de confirmação para duas ou mais teorias rivais. O que Stanford chamou de subdeterminação em princípio parece, de fato, depender dessas considerações. Mas, justamente por que tais condições podem soar artificiais para o realista, o autor considera que o desafio clássico não é uma ameaça real. Surpreendentemente, o problema das alternativas não concebidas levantado por Stanford não depende de duas teorias fazerem as mesmas reivindicações em relação aos fenômenos, mas de uma delas alterar significativamente o significado dos fenômenos que a outra já explicava, introduzir novos fenômenos e tornar a teoria anterior, outrora considerada aproximadamente verdadeira, apenas uma ferramenta útil em casos menos complexos. As mudanças teóricas que interessam a Stanford não constituiriam, portanto, de casos históricos de subdeterminação em princípio: nos casos reais de transição teórica uma das alternativas, ao fazer previsões sequer pensadas pela teoria rival estaria mais bem confirmada dedutivamente. E se consideramos o modelo probabilístico, teríamos teorias rivais que não dependeriam dos mesmíssimos fenômenos para seu grau de confirmação (nesse caso, mesmo tendo graus idênticos de confirmação, não seriam necessariamente subdeterminadas no sentido clássico). Isso deve ficar mais claro no desenvolvimento do texto desta seção.
} 
mesmas reivindicações sobre os fenômenos observáveis que $T_{1}$, mas difere-se em outros aspectos. $\mathrm{T}_{2}$ pode, por exemplo, excluir todas as entidades e processos inobserváveis de $\mathrm{T}_{1}$, ou substituir alguns ou todos eles por outros, ou simplesmente alterá-los, mas de tal maneira a produzir exatamente as mesmas predições observáveis. Dado que tal sorte de manobra é sempre possível, como alguém decide entre teorias rivais assim construídas? (CHAKRAVARTTY, 2007, p. 7)

Em outras palavras, a equivalência empírica é uma situação possível de duas teorias concordarem no que diz respeito à "salvação dos fenômenos" sem que ambas concordem sobre entidades e processos inobserváveis. Neste caso, não haveria critérios exclusivamente empíricos para decidir entre tais teorias.

Enquanto possibilidade lógica, a subdeterminação é uma virtual ameaça ao realismo científico e, se houver de fato uma situação tal como descrita acima por Chakravartty, qualquer decisão entre teorias se fará com base em valores não necessariamente empíricos. Aqui a ideia de uma ameaça puramente virtual é reforçada porque talvez seja o caso de que não haja de fato nenhuma situação historicamente reportada em que duas teorias alternativas sejam empiricamente equivalentes e que se diferenciem apenas nos tipos de processos e entidades inobserváveis que mencionam. Podemos citar pelo menos dois pares de teorias concorrentes cujas consequências empíricas são bastante próximas (quando observadas algumas condições), mas dificilmente seriam consideradas empiricamente equivalentes nos dias atuais: 1) a teoria cinética dos gases, substituindo a segunda lei da termodinâmica e 2) a relatividade especial substituindo a mecânica (e a gravitação) newtoniana. Em ambos os pares, temos equivalência somente em condições muito específicas e, as consequências empíricas são ligeiramente diferentes. Aliás, essa ligeira diferença é uma das responsáveis pela mudança teórica, principalmente quando resultados mais precisos são requisitados pelos pesquisadores. Qualquer realista poderia apelar para o fato de que os resultados não são propriamente equivalentes, embora sejam bastante próximos, alegando assim que não temos aí nenhum caso de subdeterminação, apenas progresso em aproximar da realidade.

Por essa razão, e para acomodar os casos historicamente relevantes de transição teórica, Stanford faz uma distinção importante entre subdeterminação em princípio (isto é, enquanto mera possibilidade 
lógica) e subdeterminação recorrente na história da ciência. Uma subdeterminação em princípio não seria, segundo o autor, razão de grandes preocupações para o realista: seríamos capazes de criar um algoritmo modificando teorias em aspectos inobserváveis mantendo rigorosamente o mesmo domínio de fenômenos que corroboram tanto a teoria original quanto a teoria modificada. Mas tais casos se apresentam mais como experimentos mentais do que como uma ameaça real. A história da ciência, todavia, nos brindaria com abundantes casos de subdeterminação recorrentes e transientes: no passado os teóricos falharam em conceber alternativas relevantes e radicalmente distintas das suas próprias teorias (tais como as descritas no parágrafo anterior). Essa falha mostra a fragilidade de inferências eliminativas ${ }^{5}$ produzirem crenças confiáveis, pois nesse tipo de inferência é preciso garantir que a teoria favorecida seja a melhor alternativa diante da evidência empírica disponível. A verdadeira ameaça para o realista, de acordo com Stanford, não viria da situação logicamente possível de equivalência empírica de

\footnotetext{
${ }^{5}$ Chamo aqui de inferências eliminativas àquelas formas de raciocínio que muitos autores convencionaram chamar de abdução ou inferência para a melhor explicação. Trata-se de um argumento indutivo que Peirce (1839-1914) sugeriu estar por trás do método científico, especificamente no que trata de escolha dentre explicações alternativas. Quando existe um fato surpreendente que não o seria caso uma hipótese fosse verdadeira, estaríamos justificados em crer que tal hipótese seria provável e aproximadamente verdadeira. Formalmente, a inferência para a melhor explicação poderia ser pensada assim:
}

$\mathrm{A} \rightarrow\left(\mathrm{B}_{1} \Lambda \mathrm{B}_{2} \Lambda \ldots \Lambda \mathrm{B}_{\mathrm{n}}\right)$

$\mathrm{B}_{1} \Lambda \mathrm{B}_{2} \Lambda \ldots \Lambda \mathrm{B}_{\mathrm{n}-1}$

$\therefore \mathrm{A}$

Para esse modo de raciocinar, a ocorrência de uma série de eventos $\left(\mathrm{B}_{1} \ldots \mathrm{B}_{\mathrm{n}-1}\right)$ que seriam implicados pelo evento $\mathrm{A}$ conta a favor de A como melhor explicação dessa série. Dentre as várias explicações para o carro $\left(\mathrm{B}_{1}\right)$, o jardim $\left(\mathrm{B}_{2}\right)$ e o telhado $\left(B_{3}\right)$ estarem molhados, a melhor parece ser a chuva (A), muito embora não haja garantias de que cada evento não tenha causas distintas. Tecnicamente, entretanto, os pesquisadores que estudam o tema tendem a dividirse sobre a equivalência entre os termos abdução e inferência para a melhor explicação que se referem a esse tipo de raciocínio. Carvalho (2013) afirma que o que há é uma família de modelos explicativos. Para o autor, alguns especialistas preferem invocar o nome de abdução para os argumentos que visam dar explicações para fenômenos surpreendentes não previstos pelos meios de explicação disponíveis até o momento e guardar o nome de inferência para a melhor explicação para a situação em que várias explicações já estavam disponíveis, dentre as quais os pesquisadores precisam decidir a mais adequada. Mas ainda que sejam vistas como ligeiramente diferentes, abdução e inferência para a melhor explicação são parecidas em seu procedimento. Procedimento que pode ser considerado bastante apropriado para uma lógica da descoberta ao revelar-se um guia heurístico suficientemente racional para uma investigação científica. No caso da inferência eliminativa, o termo se justifica quando se leva em consideração a ideia de que a melhor explicação é potencialmente a verdadeira ou mais verdadeira, tornando as demais explicações elimináveis (ou, no mínimo, apenas úteis nos domínios em que a nova teoria, por economia de cálculos ou de outro tipo qualquer, não seria inteiramente necessária). Ainda que essa diferença possa ser marcante para os estudos de metodologia da ciência, para nossos objetivos trataremos de inferência eliminativa, inferência para a melhor explicação e abdução basicamente como sinônimas, a saber, a eleição de uma explicação baseada numa série de virtudes pragmáticas ou epistêmicas. Agradeço aqui ao parecerista anônimo que recomendou uma maior explicitação do termo em questão, meu trabalho seria provavelmente menos compreensível sem esta nota. 
teorias rivais, mas das teorias alternativas que não foram consideradas. $\mathrm{O}$ autor nomeia tal subdeterminação de recorrente e transiente. "De maneira geral”, escreve Stanford,

\begin{abstract}
pensamos que nossas próprias teorias científicas são consideravelmente melhor confirmadas pela evidência que temos em mãos do que quaisquer descrições rivais da natureza que já produzimos até esse ponto da história da investigação científica. Assim, o perigo da subdeterminação recorrente e transiente, nem sempre ameaça ficar agudo a não ser que consideremos a possibilidade de haver tais sérias alternativas não equivalentes empiricamente, embora bem confirmadas, dentre as teorias que ainda sequer imaginamos ou vislumbramos. (STANFORD, 2006, p. 17)
\end{abstract}

Assim, Stanford segue a intuição de Lawrence Sklar (1981) de que nossos critérios de escolha da melhor explicação disponível frequentemente esbarram em nossa falta de imaginação. O autor mostrase ciente da dificuldade de demonstrar como o que não concebemos pode subdeterminar com ameaça real nossas teorias atuais. Por isso ele recorre ao registro histórico, procurando mostrar como foram concebidas apenas pouquíssimas teorias bem confirmadas em cada campo de pesquisa com as evidências até então disponíveis. A investigação posterior, entretanto, levou ao desenvolvimento de novas alternativas não equivalentes empiricamente, mas igualmente bem confirmadas. Deste modo, as mudanças científicas refletem, muitas vezes, alternativas compatíveis com a evidência, embora mais ou menos incompatíveis com a teoria que visam substituir. Seria isso uma espécie de incomensurabilidade - embora consideravelmente mais branda do que a de Kuhn (1962) - no sentido que há perdas e ganhos explicativos numa troca teórica, com as rivais possuindo ambições explicativas diferentes ${ }^{6}$. É possível entender melhor o problema proposto por Stanford quando ele recorre a casos históricos:

Por exemplo, na progressão histórica das teorias mecânicas desde a aristotélica para a cartesiana, para a newtoniana, até as contemporâneas,

\footnotetext{
${ }^{6}$ A incomensurabilidade como proposta por Thomas Kuhn em A estrutura das revoluções científicas (originalmente publicada em 1962) tratava da radical conversão ocorrida quando se muda o paradigma no qual opera a comunidade científica. Ao mudar um paradigma, muda-se a própria concepção de realidade, métodos de investigação e problemas relevantes. Assim, teorias de paradigmas rivais seriam incomensuráveis por se referirem a mundos diferentes, não cabendo aí nenhum critério objetivo de comparação. Tal concepção de ciência inviabilizaria qualquer teorização de que há aproximação progressiva da verdade. Stanford claramente recusa a tese kuhniana (ver STANFORD, 2006, p. 22).
} 
604 | Veritas | Porto Alegre, v. 62, n. 3, set.-dez. 2017, p. 595-623

a evidência disponível no momento em que cada teoria fora aceita oferecia suporte igualmente forte para as (então não imaginadas) alternativas posteriores. Para deixar claro, a teoria da relatividade não poderia sequer ter sido desenvolvida não fossem as anomalias evidenciais que emergiram da mecânica newtoniana. Mas a explicação teórica do movimento gravitacional dado pela teoria anterior, radicalmente diferente, era, entretanto, igualmente bem suportada pelos vários fenômenos para os quais a [teoria] mais recente já tinha providenciado uma explicação convincente. De um modo similar, eu sugiro, repetidamente nos vimos encorajados ou mesmo forçados sob o ímpeto trazido por fenômenos recalcitrantes, por anomalias inesperadas, e por outras pressões teóricas a descobrir novas teorias que se mantiveram previamente não concebidas apesar de bem confirmadas pela evidência que nos está disponível. (STANFORD, 2006, p.19)

Enquanto o primeiro passo do argumento pessimista de Stanford recorre à subdeterminação recorrente e transiente, o segundo passo (ii) ocorre através da constatação de que a mesma falha ocorrida no passado ameaça a concepção das teorias atuais, uma vez que não há diferenças significativas no processo de teorização atual em relação ao passado. Além do mais, hoje, como no passado, esse processo depende de inferência eliminativa. Este segundo passo é similar à indução pessimista original: depois de reconhecer casos de subdeterminação recorrente e transiente ao longo da história da ciência, é possível supor que o mesmo destino espera as teorias maduras da atualidade. De acordo com Stanford, o problema das alternativas não concebidas não se confunde com a metaindução pessimista, já que o foco é na subdeterminação e não no sucesso das teorias. Tentativas tais como o realismo das novas predições, ou mesmo a distinção entre postulados ativos e inativos (como no divide et impera), procuraram responder adequadamente à primeira indução, muito embora, na opinião de Stanford, tais respostas consistem em "vitórias pírricas" 8 . Os filósofos realistas, ainda conforme o autor, haviam negligenciado completamente as alternativas não concebidas:

\footnotetext{
${ }^{7}$ Vide, por exemplo, Psillos (1999) e a manobra divide et impera, já mencionados na nota 2.

${ }^{8} \mathrm{O}$ rei Pirro de Épiro teria conquistado uma vitória em dura batalha contra os Romanos na região de Ásculo, no ano de 279 a.C. perdendo, entretanto, seus melhores oficiais e muitas de suas tropas, o que o deixou sem capacidade de travar outras batalhas a seguir. Em razão de tantas perdas, o líder teria desabafado dizendo que outra vitória como aquela o teria arruinado. A analogia com o realismo científico é claro, ao tentar responder à indução pessimista original, os realistas acabariam por comprometer boa parte de suas convicções realistas e adotando uma versão de realismo muito fraca para ter um futuro promissor.
} 
Apesar de que realistas científicos ainda não consideraram seriamente ou confrontaram o problema das alternativas não concebidas em si, os anos recentes testemunharam um número de respostas realistas cuidadosas, pensativas e sofisticadas à indução pessimista original sobre a história da ciência e algumas dessas respostas, se bem-sucedidas, dar-nos-iam razões para duvidar igualmente da significância do problema das alternativas não concebidas. (STANFORD, 2006, p. 141)

É interessante ressaltar a conclusão que o próprio Stanford retira sobre as duas induções: uma tentativa bem-sucedida de resposta à primeira indução seria eficaz também contra a nova indução. É, portanto, sugerido pelo próprio proponente do problema das alternativas não concebidas que uma única solução poderia dar cabo de ambos desafios pessimistas. O que procuraremos brevemente fazer nas próximas linhas é justamente oferecer uma possível solução a ambos os problemas.

\section{O realismo experimental sofisticado de Egg (2012)}

Stanford ressaltou muito bem como as inferências eliminativas não fornecem garantia suficiente para a adesão à tese realista. Isso parece dizer respeito tanto às formulações de um realismo científico "ingênuo" baseado na inferência para a melhor explicação (modelo inferencial do qual o próprio argumento sem-milagre é uma instanciação), quanto ao realismo "sofisticado", que procura aderir somente às teorias capazes de sucessos surpreendentes e que admite seletividade sobre quais partes da teoria são mais garantidas dos que as demais. Mas a afirmação de Stanford segundo a qual não há uma resposta realista significativa para o argumento pessimista original desconsidera as formas de realismo menos dependentes de compromisso teórico. É o caso do realismo experimental de Hacking (1983) e Cartwright (1983). Estes autores se comprometem apenas com as entidades inobserváveis com as quais somos experimentalmente capazes de interagir causalmente. Por essa razão, o seu realismo não é particularmente afetado por mudanças teóricas ao longo da história da ciência. Pelo contrário, há, por parte de ambos, uma desconfiança na possibilidade de alegação de verdade aproximada às teorias, por mais bem-sucedidas que estas se mostrarem. Já a manipulação de entidades por meio de experimentos permitiria assumir sua realidade, bem como a de um pequeno número de propriedades dessa mesma 
entidade, algo que Hacking chamou de "verdades caseiras" (home truths) e Cartwright de "leis fenomenológicas", em oposição às leis fundamentais. No pensamento de Cartwright (1983), as leis fundamentais, justamente para exibir alto poder explicativo, seriam conscientemente formuladas de modo a serem falsas. A autora diferencia, portanto, a inferência para a melhor explicação, presente nas leis fundamentais, da inferência para a causa mais provável, que remete apenas a leis fenomenológicas. De acordo com a filósofa, um fenômeno pode ser sempre coberto por leis mais gerais, enquanto um relato causal não pode ser subsumido por outro sem negar a realidade da causa do primeiro relato. Isso permite, por exemplo, a Cartwright afirmar que acredita no elétron, embora haja teorias bastante diferentes sobre o mesmo:

Eu infiro para a causa mais provável, e tal causa é um termo específico, que chamamos de uma entidade teórica. Mas note que o elétron não é uma entidade de uma teoria particular. Num contexto relacionado, van Fraassen pergunta se é o elétron de Bohr, o elétron de Rutherford, o elétron de Lorenz ou outro. A resposta é que se trata do elétron, sobre o qual possuímos um grande número de teorias incompletas e às vezes conflitivas. (CARTWRIGHT, 1983, p. 92)

Tanto Hacking quanto Cartwright sofreram críticas consideráveis porque seu projeto seria inalcançável sem algum compromisso teórico. Mas a maior parte dessas críticas pode ser amenizada se tomarmos uma formulação inspirada no realismo experimental, mas mais moderada em relação ao papel que o teórico desempenha. Suárez (2008), por exemplo, sugere que o realismo experimental não é um critério para descobrir entidades e sim para justificar a crença em entidades. Adotando uma gradação nos tipos de garantia justificatória, é possível mostrar como estamos melhor justificados em alegações baseadas na interação causal do que nas alegações baseadas no sucesso teórico.

Uma boa contribuição nesse sentido é aventada por Mathias Egg (2012). Egg considera a inferência para a causa mais provável apenas uma instanciação da inferência para a melhor explicação que, entretanto, ao preencher os requisitos de ser uma inferência material, não redundante, empiricamente adequada, oferece uma garantia mais forte do que a garantia teórica: 
Em poucas palavras, eu caracterizo a garantia teórica e a causal como se segue:

1. Cada instância da inferência para a melhor explicação gera garantia teórica.

2. Uma instância da inferência para a melhor explicação gera garantia causal se e só a explicação correspondente preenche também o critério de não redundância, inferência material e adequação empírica. (EGG, 2012, p. 261)

Egg compreende o requisito de não redundância num sentido bastante forte: "Uma hipótese é não redundante exatamente se não há nenhuma outra hipótese que concorde com os [seus] resultados experimentais" (EGG, 2012, p. 261). Qualquer hipótese escolhida meramente com base nas virtudes teóricas de maior simplicidade, maior parcimônia ontológica, maior familiaridade, capacidade de explicar o maior número de fenômenos independentes, etc., será desconsiderada por Egg do critério de não redundância. Não se trata, obviamente, de esperar que fenômenos não possam ser oriundos de uma conjunção de causas múltiplas, mas de reconhecer que um relato causal (seja por causa singular, seja por múltiplas causas) é estabelecido por intervenção controlada:

Não deveria nos surpreender que um fenômeno pode em geral não ser atribuído a uma única causa, mas usualmente resulta de uma combinação de muitos fatores causais ou causas parciais. É nesse sentido que podemos contar mais do que uma narrativa causal, mas não há redundância aqui, porque todas essas narrativas são necessárias para obter a descrição causal correta. É claro que precisamos especificar em cada caso precisamente que fatores causais são relevantes (e em que grau), mas isso é geralmente possível pelos mesmos métodos (...): intervenção controlada e manipulação em condições de laboratório. (EGG, 2012, p. 262)

Egg, portanto, considera que testes experimentais são mais confiáveis do que virtudes teóricas. As virtudes teóricas seriam por si só incapazes de eliminar a não redundância e, dessa forma, elas só conferem garantia teórica. Para a garantia causal, é necessário recorrer ao experimento e à interação cuidadosamente controlada. 
É importante ressaltar aqui que Egg considera a não-redundância uma condição necessária, mas insuficiente para a garantia causal. O autor também pensa que a explicação causal é uma inferência material, seguindo a pista deixada por Cartwright de que só na explicação causal o explanans faz ocorrer o explanandum. Esse "fazer ocorrer" é assim conceituado e explicado contrafactualmente pelo realista causal:

\begin{abstract}
Se x faz ocorrer y, então (enquanto y ocorre em geral), há algumas ocorrências de y que não ocorreriam se $\mathrm{x}$ não tivesse ocorrido. A verdade desse enunciado contrafactual para pelo menos algumas ocorrências parece parte essencial do que significa para $\mathrm{x}$ causar y (apesar das dificuldades que uma descrição geral da causação em termos contrafactuais podem enfrentar), e, em conjunção com um número suficiente de y-ocorrências, implica realismo a respeito de x. (EGG, 2012, p. 264)
\end{abstract}

O realismo estaria, assim, mais próximo da explicação causal do que da explicação teórica e essa diferença entre as explicações é o que o conceito de inferência material tenta abarcar. Quando se quer falar com mais precisão sobre causação, o autor sugere ser necessário retomar a noção de propriedades causais num sentido muito próximo ao enunciado por Chakravartty (2007). Chakravartty pensa que as propriedades causais de um particular são as disposições para relações que tal particular possui, ou seja, as disposições para tal particular se comportar de certa maneira na presença ou ausência de outros particulares. Isso permitiria traçar uma linha bem demarcada sobre aquilo que, especificamente, temos mais razões para acreditar ser parte constituinte do mundo e assim menos sujeito a um descarte posterior por mudanças teóricas. Tal critério depende da distinção entre propriedades auxiliares e propriedades de detecção. Enquanto as últimas estão ligadas causalmente ao comportamento regular de nossos detectores, as primeiras são propriedades imputadas pelas teorias a particulares. Trata-se, como alerta Chakravartty, de uma distinção epistêmica, isto é, do que razoavelmente alguém pode acreditar com base na sua interação causal com o mundo. Assim, o estatuto ontológico das propriedades auxiliares é desconhecido, podendo elas serem causais ou fictícias. Com o desenvolvimento científico, algumas propriedades atribuídas por teorias podem vir a se tornar propriedades de detecção, conservarem-se como propriedades auxiliares 
ou, finalmente, serem descartadas. A figura abaixo mostra melhor essa distinção de Chakravartty (2007, p. 48):

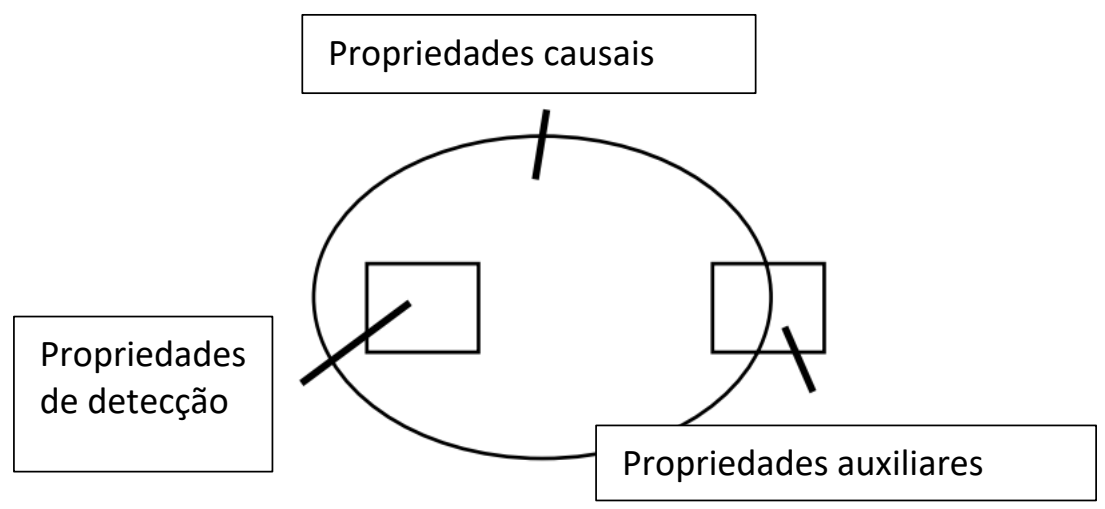

Figura 1 - Distinção entre propriedades de detecção e propriedades auxiliares

A ideia expressa na figura 1 é a de que todas as propriedades de detecção são propriedades causais. Também sugere que as propriedades causais não se esgotam naquelas que teorias atribuem a particulares. $\mathrm{O}$ realista possuiria garantia mais robusta para as propriedades de detecção (que são geralmente mantidas numa mudança científica), ao passo que propriedades auxiliares não partilham do mesmo grau de justificação. As últimas são frequentemente descartadas em mudanças teóricas. Isso conferirá uma base para um realismo seletivo (em relação às propriedades de detecção), bem como um ceticismo seletivo (em relação às propriedades auxiliares). Egg (2012) faz uso dos conceitos criados por Chakravartty (2007), chamando, entretanto, os tipos de propriedades que definem a inferência material de propriedades materiais. Tal como Chakravartty, Egg pensa que as propriedades materiais devem ser pensadas em termos de disposição para o comportamento dos particulares que as possuem. Essa disposição para comportamento, entretanto, careceria de um maior detalhamento, que Egg pensa poder encontrar na descrição da causação como manipulabilidade em Woodward (2003):

Woodward $(2003,112)$ sustenta que " para alguma coisa ser uma causa temos que ser capazes de dizer como seria ao mudá-la ou manipulá-la” A razão para este requisito é que usualmente testamos proposições causais ao intervir na suposta causa e observar se o suposto efeito muda de 
acordo. Enquanto, na descrição de Woodward, não é essencial para proposições causais que tal intervenção seja possível na prática, (ver Woodward 2003, 86-91, 127-133), é essencial que haja uma noção bem definida sobre o que significa intervir na suposta causa. (EGG, 2012, pp. 266-267)

A definição de causação de Woodward permitiria separar de um lado as leis e de outro a matéria de fato concreta. Assim, Egg chega à sua definição de inferência material: "uma inferência no modo material é a que resulta da atribuição, para uma entidade concreta, de uma propriedade para a qual há uma noção bem definida de o que significa modificá-la” (EGG, 2012, p. 266, grifo nosso).

A última das três condições necessárias para o realismo causal de Egg é a adequação empírica. Como a exigência de adequação empírica é condição advogada pelo empirismo construtivo para a aceitação de uma teoria, pode parecer estranho propor que adequação empírica tenha alguma a coisa a ver com a garantia causal e não somente com a garantia teórica. De fato, van Fraassen sustentou que a aceitação de uma teoria científica é uma questão de crer que ela "salva os fenômenos", ou seja, é a crença de que tal teoria "descreve corretamente o que é observável" (VAN FRAASSEN, 2007, p. 20). O argumento de Egg está intimamente conectado à perspectiva de Cartwright (1983) de que leis fundamentais carecem de adequação empírica à custa de seu maior poder explicativo. Caso Cartwright esteja correta, é nas leis fenomenológicas que encontraremos as descrições mais acuradas em relação aos fenômenos observáveis:

Na explicação teórica, a unificação de diversos fenômenos é essencial; sem tal unificação, uma hipótese não contaria como explanatória. Por contraste, apesar de a unificação ser certamente desejável em explicações causais, sem ela uma hipótese causal pode ser explanatória, ao confiar em matérias de fato concretas e leis fenomenológicas bastante específicas. Tendo um alcance de aplicação mais limitado, proposições sobre tais fatos e leis tem uma chance maior de serem empiricamente adequadas. (EGG, 2012, p. 268)

Egg identifica, ainda, uma ambiguidade no conceito de adequação empírica como crença de que uma teoria "salva os fenômenos". Se entendermos que isso se refere a todos os fenômenos, precisaríamos especificar o que entendemos por esse "todos". É possível, por exemplo, 
tomarmos uma interpretação estrita, a de que somente seria empiricamente adequada uma "teoria de tudo". Mas essa interpretação não permite qualquer avanço (uma teoria de tudo é recusada pelo próprio van Fraassen em $A$ imagem científica), pois exigir que uma teoria acomode empiricamente todos os fenômenos conhecidos e desconhecidos tornaria automaticamente todas as teorias atuais empiricamente inadequadas. Isso na improvável possibilidade de uma teoria que fosse capaz de salvar todos os fenômenos existentes ou, pelo menos, conhecidos. Por essa razão, Egg pensa que adequação empírica se refere a todos os fenômenos de um determinado domínio de aplicação, o que também não pode ser interpretado com muita liberalidade, sob a pena de tornar o critério muito fácil de ser atingido. Neste último caso, teríamos praticamente qualquer teoria como empiricamente adequada. Assim, a adequação empírica dependeria do estabelecimento de um domínio de aplicação nem tão vasto que permita tudo nem tão estreito que não possa ser alcançado. ${ }^{9}$ Para isso Egg sugere a consideração dos casos limites por meio de algum parâmetro que revele independência em relação aos experimentos escolhidos para serem realizados:

Em muitos experimentos, elétrons se comportam como pequenas bolas de bilhar, movendo-se por trajetórias bem definidas, sujeitos a interações locais. Ainda não poderíamos dizer que esse retrato clássico dos elétrons é empiricamente adequado, porque há outros experimentos (ex., a dupla fenda), produzindo fenômenos que são incompatíveis com a teoria clássica. O que é preciso, portanto, é de uma especificação de um domínio nem tão vasto nem tão estreito, pelo qual todos os fenômenos precisam ser salvos. Além do mais, para serem adequadas para o realismo, tais especificações devem ser objetivas no sentido de não depender do tipo de experimento que escolhermos realizar. A maneira mais comum de

\footnotetext{
${ }^{9}$ Aqui Egg acaba admitindo um critério que parece bastante vago e, neste caso, sujeito a existência de casos indecidíveis. Um meio de evitar que tal vagueza torne-se empecilho para adoção da adequação empírica como condição necessária para a inferência causal, o autor sugere tomar os casos limites em relação a algum parâmetro físico independente. Isso pode ser exemplificado pela gravitação de Newton: “A teoria da gravitação de Newton não salva todos os fenômenos gravitacionais (a precessão do periélio de Mercúrio é um famoso contraexemplo). Mas seu domínio de aplicação pode ser objetivamente circunscrito pela exigência de que as distâncias consideradas sejam grandes comparadas ao raio de Schwarzschild para os objetos considerados.” (EGG, 2012, p. 269, grifos do autor). Outra objeção seria que tal procedimento de tomar casos limites só poderia ser feito na medida em que já existe uma alternativa teórica à explicação que se quer demonstrar empiricamente inadequada. Uma resposta imediata a essa objeção é que a existência de alternativa teórica viola o critério de não-redundância, retirando das concorrentes a possibilidade de fornecer garantia causal. Desse modo, a mera ocorrência da competição exige o alargamento do domínio de fenômenos que precisam "ser salvos", o que, frequentemente, acaba favorecendo uma das competidoras.
} 
612 | Veritas | Porto Alegre, v. 62, n. 3, set.-dez. 2017, p. 595-623

alcançar isso é considerando casos limites em respeito a algum parâmetro físico. (EGG, 2012, p. 269)

A inadequação empírica é uma condição necessária para evitar justamente que explicações causais sejam oferecidas sem que o proponente esteja comprometido com a realidade das causas inferidas. Trata-se de uma crítica feita ao realismo experimental por Hitchcock (1992). Hitchcock faz uso do experimento da dupla fenda para alegar que é possível aceitar uma explicação causal sem crer na sua verdade. A experiência feita por Young é bem conhecida: um feixe de elétrons é projetado de modo a atravessar uma tela opaca com duas fendas e alcançar uma tela sem fendas. Quando apenas uma das fendas está aberta, obtemos imagens similares e a expectativa é a de que ao fazermos o feixe passar por duas fendas simultaneamente, as imagens seriam apenas superpostas. Mas o caso é que os feixes apresentam o comportamento de uma interferência. Hitchcock ressalta que o choque entre o fóton e o elétron que ocorre na tentativa de determinar por qual fenda tal elétron passa acabaria por destruir a interferência. Assim, quando o elétron é detectado passando pela primeira fenda ou pela segunda, não há interferência resultante. A explicação causal aqui seria a de que o fóton impõe momentum ao elétron, alterando sua trajetória e destruindo o padrão de interferência. Trata-se, sugere Hitchcock, de uma explicação que contradiz tanto a mecânica quântica ortodoxa quanto a maioria das suas formulações "heréticas", já que a as teorias envolvidas (exceção feita aos que insistem na teoria das variáveis ocultas) pressupõem a impossibilidade de possuirmos os valores do momentum e da posição simultaneamente. Como o elétron, de acordo com a mecânica quântica, não pode ter uma trajetória contínua clássica e a interferência seria causalmente explicada pela trajetória do elétron, Hitchcock pensa ter um caso de explicação causal que não demanda crença, mas apenas aceitação:

Essas explicações causais, portanto, oferecem boas candidatas a contraexemplo para a afirmação de que a aceitação de uma explicação causal envolve comprometimento com a crença na verdade da narrativa causal. As explicações causais das relações de incerteza pareceriam ser aceitas, mas não acreditadas. (HITCHCOCK, 1992, p.172) 
Suárez (2008) recusa que o relato de Hitchcock seja propriamente o relato de uma explicação causal por falta de materialidade. Para o espanhol, não só não há garantia causal na descrição do padrão de interferência, como há garantia causal contra tal relato:

\begin{abstract}
Estamos invocando a interação fóton-elétron para explicar não o padrão de interferência, mas antes seu desaparecimento quando detectamos o elétron na primeira tela. Então, a estória causal pressupõe que se não detectamos a passagem do elétron na primeira tela, a trajetória do elétron seria causalmente responsável pelo padrão de interferência. Em outras palavras, estamos pressupondo que o padrão de interferência num experimento de dupla fenda é causalmente explicado por trajetórias dos elétrons. E essa "explicação" do padrão de interferência não é causal - se é que é mesmo uma explicação - uma vez que "não seria acreditada como verdadeira por ninguém exceto o mais teimoso crente em variáveis ocultas". E isso não é simplesmente sobre fundamento teórico ou interpretativo, mas sobre o fundamento da evidência experimental contra a existência de trajetórias clássicas na mecânica quântica, na forma como todos os tipos de experimentos de interferometria. (SUÁREZ, 2008, pp. 151-152 grifos do autor)
\end{abstract}

Para Suárez, uma vez que a explicação causal é um termo de sucesso, um relato só pode ser considerado causal quando se acredita que a causa é verdadeira. Quando não se acredita na realidade da causa, se houver aí alguma explicação, é por tratar-se de uma explicação teórica e não causal. A garantia justificatória da interação fóton-elétron é a mesma de qualquer explicação teórica: dada uma lei teórica, pode-se pensar o fenômeno como deduzido dela. E, nesse caso, uma explicação teórica não requer verdade. Em relação ao exposto, para Suárez pouco importa se o vocabulário é tipicamente causal. A ideia de que um fenômeno é subsumido por uma explicação teórica com vocabulário causal é bastante diferente da explicação que recorre a causas reais dos fenômenos.

Ao contrário de Suárez, Egg, em sua proposta de realismo causal, prefere contestar a relevância do contraexemplo em sua falha de adequação empírica. Apesar de Hitchcock pretender ressoar a ideia de van Fraassen segundo a qual crer e aceitar uma teoria são passos diferentes, Matthias Egg tece um comentário relevante sobre a alegação de Hitchcock: seu explanans não é empiricamente adequado, condição necessária para que uma teoria seja aceitável ao empirismo construtivo. Eis o que diz Egg: 
Agora, o explanans no exemplo de Hitchcock é empiricamente adequado? Ele certamente "salva os fenômenos" para este experimento particular, mas não temos que procurar muito longe por fenômenos que são incompatíveis com esse enquadramento clássico; o padrão de interferência no experimento original de dupla fenda (sem detecção de qual é a fenda por meio da qual cada elétron passa) não pode ser explicado por trajetórias clássicas e interações locais. Portanto, a estória de Hitchcock só serve como um contraexemplo à validade da inferência pela causa mais provável se não requerermos que explicações causais sejam empiricamente adequadas. (EGG, 2012, p. 272)

A inadequação empírica seria a razão pela qual a explicação do padrão de interferência na experiência da dupla fenda não é um relato causal genuíno e o mesmo não poderia ser utilizado como contraexemplo à distinção entre garantia causal e garantia teórica. A explicação clássica da dupla fenda só seria empiricamente adequada se se admitir um conceito muito flexível de adequação empírica. A referida explicação clássica não salva todos os fenômenos relevantes do domínio. Assim, o relato de Hitchcock não passa no critério da adequação empírica, condição necessária, mas insuficiente para uma inferência para a causa mais provável.

Dessa forma, somente a conjunção das três condições, a saber, inferência material, não-redundância e adequação empírica, permite afirmar uma causa mais provável e, devido justamente à necessidade de cada uma das condições supramencionadas, a garantia justificatória da inferência para a causa mais provável não seria uma matéria de convencionalismo arbitrário, como tentaram alegar alguns críticos de Cartwright ${ }^{10}$. Assim, quando o assunto é a crítica de que o realismo experimental possui uma dependência tácita de teorias para sustentar a existência de entidades, Egg propõe que seu realismo causal tem uma resposta bastante simples e clara: teorias atribuem propriedades materiais e formais às entidades. As propriedades formais só conferem garantia teórica (por inferência para a melhor explicação) e as propriedades materiais conferem garantia causal (via inferência para a causa mais provável) de modo que o realista causal pode se comprometer com algumas partes da teoria sem se comprometer com todo o resto.

${ }^{10}$ Nomeadamente Hitchcock(1992) e Reiner e Pierson (2008). 


\section{Respondendo aos dois desafios historicistas}

Pensamos que, com os cuidados sugeridos por Egg, uma proposta realista que afirma conhecimento causal das propriedades das entidades inobserváveis permanece uma via defensável de resposta à descontinuidade que as teorias científicas sofreram historicamente. O realismo de Egg pode anunciar que o conhecimento sustentado com garantia causal tende a ser retido, enquanto o grau de comprometimento com a garantia teórica deve ser menor, permitindo modificações e eliminações futuras. A falta de pelo menos um dos requisitos permite um comprometimento menor com a existência de uma entidade ou a algumas propriedades de uma entidade e à totalidade de uma teoria como um todo. Isso não só cria um critério para o que estamos mais justificados em crer que permanecerá em futuras mudanças teóricas, como explica os casos paradigmáticos de ambos os argumentos pessimistas baseadas na história da ciência: a ausência de materialidade (no sentido exposto por Egg de sermos capazes de modificar uma propriedade) faz com que o éter ou o calórico, embora tenham papéis causais em suas teorias de origem, não forneçam garantia causal. A ocorrência de redundância é motivo para recusar garantia causal ao flogisto, ou melhor, ao ar deflogisticado. A redundância ocorre pela emergência da hipótese de que o oxigênio seria a causa mais provável dos mesmos fenômenos, concorrendo com as explicações causais anteriores. Ao contrário do que ocorre com explicações teóricas, em que uma lei mais geral coexiste em contextos diferentes com uma lei menos geral, um relato causal não é subsumido por outro e, assim, não é possível manter ambos relatos. Já o requisito de adequação empírica explica porque um relato aparentemente causal como é o da explicação da mecânica clássica para a experiência da dupla fenda falha em fornecer garantia causal. Se uma teoria não consegue adequar-se aos fenômenos abrangidos por um domínio ampliado, não há garantia causal para tal explicação. O mesmo pode ser dito sobre a gravitação de Newton (mencionado na nota 7) e sobre a explicação de Bohr para o decaimentobeta no núcleo atômico. ${ }^{11}$ A dificuldade em fazer previsões empiricamente

\footnotetext{
${ }^{11}$ Enquanto Wolfgang Pauli propôs a existência do neutrino, Niels Bohr preferiu propor que o princípio da conservação da energia falhava em nível nuclear. Um experimento conduzido por Reines e Cowan em 1950 permitiu avançar na direção da existência da entidade inobservável, produzindo um fenômeno de correlação entre a o status do reator nuclear e a razão de decaimento beta no detector. Para uma descrição mais pormenorizada do processo de detecção do neturino, ver Egg (2012) pp. 272-278.
} 
adequadas em domínios mais alargados abre caminho para alternativas teóricas e impede que o realista causal fique apegado a essas explicações que fornecem apenas garantia teórica. Neste caso, uma mudança teórica também não é algo que coloque em risco as conviç̧ões seletivas do realista causal.

Sobre a nova indução de Stanford, Chakravartty (2008) não nega que seja um novo argumento antirrealista, mas a novidade deste argumento, como já antecipamos, não se traduz em dificuldade adicional para o realista seletivo. Chakravartty até brinca com a ideia de o problema das alternativas não concebidas ser "um novo chapeuzinho vermelho" (2008, p. 153), pois embora o desafio seja novo, as respostas produzidas pelo realismo experimental à metaindução pessimista são claramente respostas capazes de barrar essa nova indução:

A boa notícia é que há considerável evidência em suporte à ideia de que se alguém consegue forjar contato significante com entidades, elas são retidas quando teorias que as envolvem mudam ao longo do tempo. Numerosas teorias sobre a natureza do elétron, por exemplo, já vieram e já foram desde que J.J.Thomson especulou que os 'raios catódicos' sobre os quais ele estava experimentando em 1897 poderiam ser compostos de uma corrente de 'corpúsculos', mas a entidade mesmo ainda tem um lugar na teoria atual. Há um caso prima facie, ao que parece, de que o realismo de entidades pode ser um refúgio para o realista em face à descontinuidade histórica. (CHAKRAVARTTY, 2007, p. 31)

Chakravartty chama atenção para o fato de Stanford considerar que qualquer seletividade do realista conferiria apenas "vitórias pírricas". Isso porque o realista precisaria sacrificar muito de seu realismo de modo a conter o dano causado pela nova indução. Por outro lado, o realista tampouco seria capaz de prospectivamente dizer que elementos de uma teoria atual devem ser retidos numa substituição teórica futura. Embora reconhecendo os problemas que o realismo experimental enfrenta, Chakravartty admite que o realismo proposto por Hacking e Cartwright responde satisfatoriamente ao problema da indução pessimista original ao propor uma seletividade, priorizando a garantia causal. Assim, por meio dos critérios do realismo experimental, é possível assumir que propriedades bem confirmadas são candidatas a se perpetuarem em novos arranjos futuros: 
Um conhecimento de propriedades e relações, eu assumo, não é uma vitória pírrica para o realista; é substancial. Stanford frequentemente escreve como se teorias e entidades fossem as unidades do conhecimento científico com os quais os realistas precisam se comprometer, e assim falha em notar como propriedades bem confirmadas persistem através de mudanças teóricas nas teorias e nas entidades que elas descrevem. Um realismo sofisticado é mais refinado do que ele [Stanford] permite, é por isso que suas preocupações sobre vitórias pírricas e critérios prospectivos falham seu alvo. (CHAKRAVARTTY, 2008, p. 155)

O autor em questão, também pensa podermos determinar diferentes graus de garantia justificatória à medida que se possui maior ou menor capacidade de manipular causalmente as propriedades em questão. A ideia de que devemos ser realistas sobre propriedades e relações permite a Chakravartty admitir a mudança da teoria do flogisto para a do oxigênio sem ver nisso qualquer problema para sua própria versão de realismo sofisticado: as propriedades conhecidas pela interação com o 'ar deflogisticado' permanecem presentes no 'oxigênio', embora não correspondam a uma mesma entidade. Nas teorias em que se possui maior conhecimento causal detalhado há maior garantia e nas teorias que esse conhecimento é mitigado há menos certeza. Neste caso, Stanford falha ao pensar que o realismo é questão de tudo ou nada.

A resposta de Chakravartty ao problema das alternativas não concebidas inova, segundo Egg, ao oferecer um critério para um realismo seletivo que sirva tanto retrospectivamente quanto prospectivamente. Isto é, a adoção da seletividade de Chakravartty permite para apontar no passado porque é que certas entidades e propriedades foram abandonadas. Ao mesmo tempo tal critério consegue prever quais pontos das teorias atuais temos mais garantia de que serão conservados num eventual progresso científico. Comparado às elaborações do divide et impera de Psillos $(1996,1999)$ e à distinção entre postulados ativos (working posits) e postulados pressuposicionais (presuppositional posits) de Kitcher (1993), a proposta de Chakravartty não parece ser atingida pela crítica de Stanford abaixo reproduzida:

Embora perfeitamente natural, essa sugestão [de separar postulados ativos e inativos] parece entrar em conflito com todo número de postulados teóricos descartados aos quais foram atribuídos papéis causais diretos na produção de fenômenos por práticas explanatórias bemsucedidas de suas respectivas teorias. Aos tão familiares exemplos como o 
flogisto e o fluido calórico, vimos que podemos razoavelmente somar as gêmulas de Darwin, as estirpes de Galton e os biósforos de Weismann. (STANFORD, 2006, p. 172)

Se a descontinuidade de entidades com papéis causais ameaça aquele realismo sofisticado do divide et impera, isso não ocorre ao realismo de Chakravartty, o qual sustenta a permanência de propriedades e não de entidades. Então, mesmo que a sugestão de Stanford proceda e que se reconheça que teorias do passado conferiam papel direto causal ao calórico, é possível mostrar que as propriedades causais mantidas em novas teorias sobre o calor eram propriedades de detecção e as propriedades descartadas eram auxiliares.

Talvez aqui a ameaça não venha da descontinuidade histórica, mas de outra questão levantada por Stanford: não seria a proposta de Chakravartty uma "vitória pírrica"? Isto é, basear o conhecimento apenas de propriedades mereceria o título de "realismo"? Egg pensa que o acento nas propriedades é base também para a crença na realidade de entidades, que são unidades formadas pela convergência de propriedades:

Entretanto, o fato de que propriedades são o foco primário da resposta do
realista à nova indução não implica que esse comprometimento é limitado
a propriedades somente. Uma vez que a realidade de certas propriedades
é estabelecida, o realista pode argumentar para a existência de entidades,
baseado no fato de que propriedades frequentemente se ajuntam para
formar unidades interessantes (Chakravartty [2007], pp. 63-6). Em
alguns casos, a realidade de algumas entidades segue mesmo mais
diretamente, como poderá ser visto na hipótese atômica (...). (EGG, 2014,
p. 10)

Embora concorde com uma abordagem causal, Egg admite que a distinção fornecida por Chakravartty (2007) entre propriedades auxiliares e propriedades de detecção pode ser pouco esclarecedora. Chakravartty sugere que o comprometimento epistêmico deve estar assentado apenas numa "interpretação mínima" das equações, de modo que tudo o mais deve ser considerado propriedade auxiliar. Mas o contrário parece ser o caso, isto é, primeiro distinguimos entre propriedades auxiliares e de detecção e depois damos uma interpretação mínima das equações. Esse recuo é devido à própria elucidação de Chakravartty sobre os conceitos de "propriedade de detecção" e "interpretação mínima" a partir da ideia de 
conexão causal ou contato causal além dos quais toda interpretação seria excedente. O problema passaria então a ser o da identificação do que é que conta como contato causal significante. Esse passo, pensa Egg, é dado pelo seu estabelecimento do já mencionado trio de condições necessárias para uma inferência causal: modo material, não redundância e adequação empírica. As três condições requeridas por Egg (2012) são uma chave para a demarcação requerida por Chakravartty (2007) entre propriedades auxiliares e propriedades de detecção:

Em suma, confiar na caracterização de garantia causal em termos dos três supramencionados critérios nos fornece um caminho direto para distinguir propriedades de detecção das propriedades auxiliares: as primeiras são simplesmente aquelas para as quais possuímos garantia causal. Isso satisfaz muito bem a consideração de Chakravartty: a inferência material decifra uma precondição crucial para o que ele chama 'forjar significante contato causal'; adequação empírica captura sua ideia de que propriedades de detecção nos permitem fazer previsões, retrodições, e assim por diante; e a não redundância expressa a crença de que essas propriedades são indispensáveis para alcançar esses objetivos. (EGG, 2014, p.13)

Há, entretanto, um pormenor que deve ser explicitado antes de dizer que o realismo causal responde satisfatoriamente ao desafio de Stanford: o requisito de não redundância precisa ser entendido no sentido fraco, isto é, falível a ponto de permitir que futuramente surja alguma alternativa. Caso contrário, seria impossível haver alternativa a ser concebida. Assim, Egg pode sugerir que as propriedades afirmadas com base numa inferência material, na adequação empírica e na não redundância (no sentido fraco) são provavelmente não redundantes no sentido forte, isto é, são imunes ao desafio de Stanford.

Egg argumenta pela superioridade de seu realismo causal em relação ao semirrealismo de Chakravartty a partir do exemplo do éter de Maxwell. Não seria muito fácil defender prospectivamente que o comprimento de onda é uma propriedade de detecção e a substancialidade do meio etéreo é propriedade auxiliar. De posse da crença de Maxwell, a saber, que nenhuma energia se propaga sem um meio substancial, sempre que detectarmos uma onda eletromagnética estaremos também justificados em acreditar ter interagido com o éter. A razão para não considerar a substancialidade do éter como uma propriedade de detecção 
fica clara no realismo causal: considerando o modo de inferência material aquele em que "há uma noção bem definida de o que significa modificar a propriedade em questão", temos que a amplitude de onda de luz satisfaz o conceito, ao passo que o éter não. Assim, mesmo que alguém subscreva a crença de Maxwell num meio de propagação da onda eletromagnética, ele não seria capaz de dizer o que seria modificar as propriedades desse meio. Se, ao contrário, alguém quiser sugerir que existem meios de modificar a substancialidade independentemente da capacidade de transferência de energia, então a possibilidade de um campo eletromagnético sem um meio substancial deixa de ser uma alternativa não concebida. No primeiro caso o defensor do éter não passaria no critério de inferência material. No segundo caso, Egg sugere haver a violação do requisito de não redundância no sentido fraco e a hipótese deixaria de ser não concebida, passando a ser uma alternativa.

O realismo causal de Egg não seria, dessa forma, ameaçado pela nova indução pessimista de Stanford. De acordo com o realista causal, uma explicação para isso seria o fato de que o formato do problema das alternativas não concebidas visa prioritariamente a teorização fundamental, ao passo que o realista causal se preocupa mais com as explicações causais de fenômenos experimentais. A capacidade, entretanto, de o realismo causal ser mais ou menos bem-sucedido em sua previsão do que poderá ser descartado e do que provavelmente será mantido numa modificação teórica futura precisa ser medida caso a caso:

Isso mostra que, ao esboçar os recursos conceituais do realismo causal, a distinção entre propriedades de detecção e propriedades auxiliares pode se tornar suficientemente precisa para sublinhar um realismo com o prospecto de resistir ao argumento de Stanford das alternativas não concebidas. O quanto esse prospecto é alcançado dependerá em quão bem essa explicação se encaixa no registro histórico do raciocínio científico (...). $\left(\mathrm{EGG}, 2014\right.$, p. 14) ${ }^{12}$

\footnotetext{
${ }^{12} \mathrm{O}$ apelo anterior ao registro histórico se faz necessário porque o próprio Stanford fez isso, alegando que Jean Perrin, em seu estudo sobre o movimento browniano, também estava sujeito ao problema das alternativas não concebidas. Por isso Egg procurou fazer da hipótese atômica um estudo de caso a seu favor, o que não reproduziremos aqui por falta de espaço.
} 


\section{Conclusão}

Egg pretendeu ressaltar os três aspectos já mencionados aqui: a distinção entre propriedades de detecção e propriedades auxiliares, a diferença entre teorização fundamental e explicação causal de fenômenos e, por último, o processo que começa nas propriedades de detecção e termina na inferência para a realidade de uma entidade inobservável. Uma atenção dirigida aos três aspectos supramencionados permite responder tanto à antiga quando à nova indução pessimista, pois as entidades, propriedades e relações mais garantidas são justamente as que podemos inferir de nosso contato experimental. Assim, distinguindo entre propriedades formais (auxiliares) e propriedades materiais (de detecção), somos levados a propor que as propriedades materiais permanecerão mesmo quando a teoria em que tais propriedades aparecem seja falsa e ainda que a teoria em questão possa vir a ser substituída por uma alternativa hoje ainda não concebida. Igualmente o foco na explicação causal em detrimento da teorização fundamental coloca o realismo causal menos dependente de virtudes teóricas. E virtudes teóricas (tais como o sucesso surpreendente) não impedem uma teoria de ser considerada falsa e nem evitam a redundância que está na origem do problema das alternativas não concebidas. Por último, o entendimento de que uma entidade é definida por um conjunto de propriedades dá segurança para afirmar a realidade daquelas entidades inobserváveis que reúnem propriedades materiais, diferenciando-se daquelas entidades que hoje só habitam os livros de história da ciência e são consideradas por eles como meras ficções.

\section{Referências bibliográficas}

CARTWRIGHT, N. How the Laws of Physics Lie. Oxford: Clarendon, 1983.

CARVALHO, Fábio Tenório de. Inferir Explicações e Explicar Inferências:Uma abordagem pragmático-transcendental da Inferência à Melhor Explicação. Tese de Doutorado, UFMG, 2013.

CHAKRAVARTTY, Anjan. A Metaphysics for Scientific Realism: Knowing the Unobservable. Cambridge University Press, 2007. 
622 | Veritas | Porto Alegre, v. 62, n. 3, set.-dez. 2017, p. 595-623

. What you don't know can't hurt you: Realism and the unconceived. Philosophical Studies 137 (1):149 - 158 (2008).

EGG, Matthias. Causal Warrant for Realism about Particle Physics. Journal for General Philosophy of Science / Zeitschrift für Allgemeine Wissenschaftstheorie 43 (2):259280 (2012).

. Expanding Our Grasp: Causal Knowledge and the Problem of Unconceived Alternatives. British Journal for the Philosophy of Science (2014) 67 (1):axuo25. pp.1-27.

HACKING, Ian. Representing and Intervening: Introductory Topics in the Philosophy of Natural Science. Cambridge University Press, 1983.

HITCHCOCK, Christopher Read. Causal explanation and scientific realism. Erkenntnis (1992) 37 (2):151 - 178.

KITCHER, Philip. The Advancement of Science: Science Without Legend, Objectivity Without Illusions. Oxford University Press, 1993.

KUHN, Thomas S. The Structure of Scientific Revolutions Vol.. The University of Chicago Press, 1962.

LAUDAN, Larry. A confutation of convergent realism. Philosophy of Science 48 (1):19-49 (1981).

LIPTON, Peter. Is the Best Good Enough? Proceedings of the Aristotelian Society 93:89-104 (1993).

. Truth, existence, and the best explanation. In A. A. Derksen (ed.), The Scientific Realism of Rom Harré. Tilburg University Press, 1994.

LYONS, Timothy D. Scientific Realism and the Pessimistic Meta-modus Tollens. In CLARKE, Steve; LYONS, Timothy D (eds.). Recent Themes in the Philosophy of Science: Scientific Realism and Commonsense. Dordrecht: Kluwer, 2002, pp 6390.

PIERSON, Robert \& REINER, Richard. Explanatory warrant for scientific realism. Synthese $161(2): 271-282$ (2008).

PSILLOS, Stathis. Scientific realism and the 'pessimistic induction'. Philosophy of Science 63 (3):314 (1996). . Scientific Realism: How Science Tracks Truth. Routledge, 1999. 
T. Oliveira - Uma solução baseada no realismo experimental para dois argumentos pessimistas | 623

PUTNAM, H. Mathematics, Matter and Method. Cambridge University Press, 1975.

SANKEY, Howard. Scientific Realism. Theoria 48 (98):35-54 (2001).

SKLAR, L. Do unborn hypotheses have rights? Pacific Philosophical Quarterly 62, 17-29 (1981).

STANFORD, P. Kyle. Exceeding Our Grasp: Science, History, and the Problem of Unconceived Alternatives. Oxford University Press, 2006.

SUÁREZ, Mauricio. Experimental realism reconsidered: How inference to the most likely cause might be sound. In CARTWRIGHT, N; HARTMANN, S; HOEFER, C \& BOVENS, L. (eds.). Nancy Cartwright's Philosophy of Science. Routledge, 2008, pp. $137-163$

VAN FRAASSEN, Bas C. A imagem científica. Trad. Luiz Henrique de Araújo Dutra. Editora Unesp; Discurso Editorial, 2007.

VICKERS, Peter. A Confrontation of Convergent Realism. Philosophy of Science 8o (2):189211 (2013).

WOODWARD, James. Making Things Happen: A Theory of Causal Explanation. Oxford University Press, 2003.

\section{Endereço postal:}

Departamento de Filosofia do Colégio Pedro II

Campo de São Cristóvão, 177 - Rio de Janeiro - RJ, Brasil

Data de recebimento: 30-09-2017

Data de aceite: 04-12-2017 